\title{
Triorchidism: a rare case report
}

\author{
Anita R. Gune ${ }^{1}$ and Rahul P. Gune $2^{2^{*}}$
}

\begin{abstract}
Background: The presence of an extra testis is referred to as polyorchidism and is a rare congenital anomaly. There are with less than 200 cases reported, globally. It carries with it, a risk of malignancy making astute diagnosis and follow-up important. The management protocol of polyorchidism is ambiguous with factors such as age of the patient, location, size and anatomical organization of the testicular system playing an important role.

Case presentation: A 28-year-old male who presented with a non- tender scrotal swelling which on clinical and sonographic examination was diagnosed to be a case of triorchidism (the most common type of polyorchidism). Type 2 polyorchidism with normal epididymis and vas deference was observed. The case was conservatively managed and regular follow-up was advised.

Conclusion: Polyorchidism is a rare congenital anomaly. Patients with Polyorchidism can be conservatively managed. The reproductive potential and possible concomitant symptoms and complications including cryptorchidism, inguinal hernia and torsion will affect the management strategy. However, if the supernumerary testis is suspected of undergoing neoplastic transformation, it should be resected.
\end{abstract}

Keywords: Gonadal dysgenesis, Ultrasonography, Vas deferens

\section{Background}

Polyorchidism is a rare congenital abnormality seen in the development of the genitourinary tract. Less than 200 cases of Triorchidism are reported in literature [1]. Most cases are asymptomatic and are diagnosed as incidental findings. The extra testis is commonly present in the Scrotum (66\%), inguinal canal (23\%) or retroperitoneum (9\%) [2]. On occasions, these patients present with infertility, torsion or malignancy.

\section{Case presentation}

A 28 years old male presented with a complaint of a painless swelling in the left side of the scrotum noticed since a few weeks. On physical examination, a small, mobile, smooth swelling was noted at the base of scrotum, superio-lateral to the left testicle and smaller than the testicle (Fig. 1). Both right and left testes with epididymis and vas were normal on palpation. His semen parameters were

\footnotetext{
${ }^{*}$ Correspondence: guneurology@gmail.com

${ }^{2}$ Nirmal Nursing Home, Mirajkar Tikkti, Kolhapur, Maharashtra 416002, India

Full list of author information is available at the end of the article
}

normal. On Ultrasound, there were three testes seen in the scrotal sac, one on the right side and two on left (Fig. 2). The testes showed normal size, shape and margins with a smooth homogenous echo texture. Volume was calculated by ultrasound measurements [3].

Testis $1=$ Right side measured $41 \times 25 \times 20 \mathrm{~mm}$ (volume-14.5 ml)

Testis $2=$ Left side measured $41 \times 25 \times 21 \mathrm{~mm}$ (Volume $-15.2 \mathrm{ml}$ ) and

Testis $3=$ Left side supernumerary testis measured $37 \times 23 \times 22 \mathrm{~mm}$ (Volume-13.2 ml).

The third testis was lying superior to the left 2 nd testis. All three organs showed normal blood flow. No testicular enlargement or hydrocele was noted. There was no abnormality of the epididymis. Two cord structures were identified, one on each side. Based on the clinical and sonographic evaluation diagnosis was type 2 polyorchidism. Given the patient's age and need to maintain fertility, conservative management approach was opted 


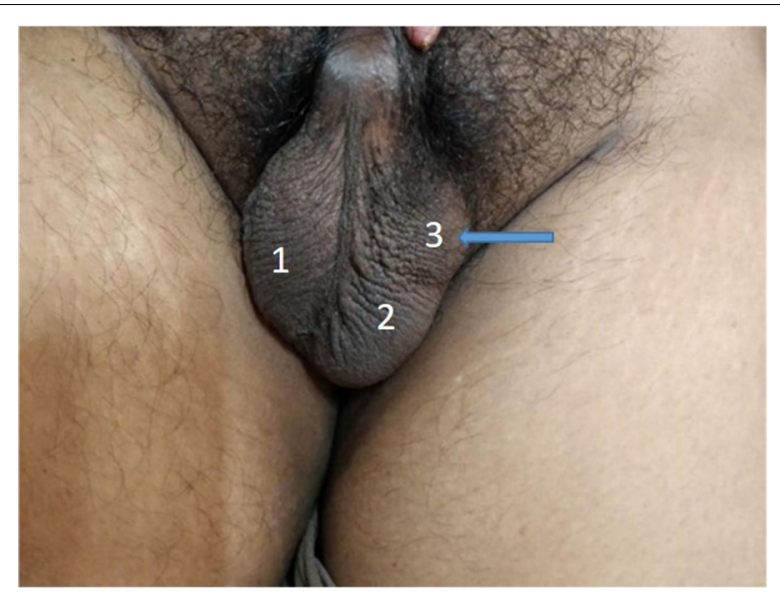

Fig. 1 Clinical presentation of double left testicle

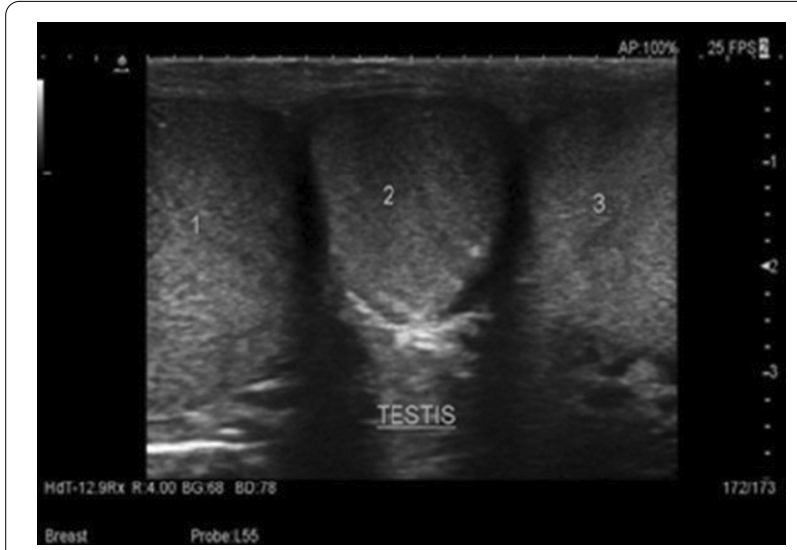

Fig. 2 Sonogram of scrotum demonstrating presence of extra testis

for. The patient was counselled on self-examination and regular follow-up and advised to revert if any change in size, shape or presence of pain was noticed.

\section{Discussion}

Triorchidism is a rare congenital anomaly. Less than 200 cases of Triorchidism have been reported in literature [1]. According to previous studies, the extra testis is commonly present in the Scrotum (66\%), inguinal canal (23\%) or retroperitoneum (9\%) [2]. A high number of patients with triorchidism are detected in the 20-40 year age group $[1,2,4-6]$.

Compared to the right testis, the left testis is usually larger and has different topographic vascular anatomy and hence is more prone to divisions leading to polyorchidism [4]. Interestingly, Hassan et al. [5] have reported a case with triorchidism in the right testis. This can be explained by variations in testicular size.
Triorchidism, typically presents as a non-tender swelling of the scrotum. In a case studied by Aziz W et al., a 30-year-old male presented with a non-tender swelling of the testis and infertility. Infertility was attributed to faulty division of the testes [6].

Size of the testes solely depends on the division of testes. This is obvious by the variation of sizes reported in various studies. The present case report illustrates testes of equal size on both the sides. However, the supernumerary testis on the left side was smaller in size. Interestingly, Kheirandish et al. [1] reported a case where both the testes on the left side were of equal size and hence the supernumerary one was difficult to differentiate. In a case studied by Abduljabbar et al. [2], variation in size of both the testes on the left side was seen. However, the right testis was comparatively larger than both the left ones.

Primordial testis starts developing from the primitive genital ridge at about 6 weeks of gestational age. The primitive genital ridge lies medial to the mesonephric ducts. Shape of the testis is achieved by the 8th week. Epididymis and vas deferens start developing from the Wolfian duct (Mesonephric) around the same period. A horizontal or longitudinal plane duplication of the genital ridge takes place, which results in polyorchidism.

On the basis of embryological development, Leung gave the first classification (1988) which was later modified by Thum $[7,8]$.

Type-1 Division of the genital ridge only separating only a small part of the genital ridge that is not in contact with the rete testis. This results in supernumerary testis without an epididymis or vas and has shown no attachment to the usual testis

Type-2 Division of genital ridge occurs in the region where there is attachment of the primordial gonads to the metanephric ducts. Due to this, the supernumerary testis drains into the epididymis of regular testis and they share a common vas

Type-3 Complete transverse division of mesonephros as well as genital ridge, results in the supernumerary testis having its own epididymis and both epididymis of the ipsilateral testes draining into one vas

Type-4 Vertical division of the genital ridge and mesonephros results in complete duplication of testes, epididymis and vas

The case in the present report demonstrated Type 2 polyorchidism. This is also reflected by the absence of complaints other than non-tender swelling. However, 
Type 2 polyorchidism was reported in the study done by Hassan et al. and Aziz et al. $[5,6]$ which was reflected as reproductive abnormalities such as oligoasthenoteratozoospermia and infertility.

Management of polyorchidism depends on the age, location and organ architecture among other factors. A conservative approach with regular follow-up with emphasis on self-examination is carried out when maintenance of reproductive function is required. Resection is advised in case of suspicion of malignancy.

\section{Conclusion}

Polyorchidism must be considered in the differential diagnosis of solid testicular masses. Ultrasound provides an easy, cost effective tool for diagnosis while MRI allows functional classification. On diagnosing polyorchidism, the associated complications such as undescended testes, inguinal hernia, infertility and potential risk of malignancy must be borne in mind. Further management depends on the position of the supernumerary testicle being scrotal or ectopic. Additionally, the reproductive potential and possible concomitant symptoms and complications must be considered while choosing orchidectomy versus conservation and follow-up. These strategies would appear to be safe to preserve a viable intra scrotal supernumerary testis found incidentally.

\section{Abbreviations}

MRI: magnetic resonance imaging.

\section{Acknowledgements}

We thank the patient for approving consent to participate in the study and consent to publish the same.

\section{Author's contributions}

AG: Concepts, Design, Definition of intellectual content, Literature search, Clinical studies, Experimental studies, Data acquisition, Data analysis, Statistical analysis, Manuscript preparation. RG: Clinical studies, Experimental studies, Manuscript editing, Manuscript review, Guarantor, Definition of intellectual content. Both the authors read and approved the final manuscript.
Funding

Nil.

Availability of data and material

Will be provided on request.

Ethics approval and Consent to participate

Consent was obtained from the participant.

\section{Consent for publication}

Awritten consent was obtained from the participant.

\section{Competing interests}

The authors declare that they have no competing interests.

\section{Author details}

${ }^{1}$ Department of Anatomy, D.Y. Patil Medical College, D.Y. Patil Education Society, Kolhapur, Maharashtra 416006, India. ${ }^{2}$ Nirmal Nursing Home, Mirajkar Tikkti, Kolhapur, Maharashtra 416002, India.

Received: 29 April 2020 Accepted: 28 December 2020

Published online: 11 January 2021

\section{References}

1. Kheirandish P, Chinegwundoh F (2010) An unusual case of triorchidism. JRSM Short Rep 1(6):1-3

2. Abduljabbar AH (2015) A case report: triorchidism; is a rare mistaken cause for extra testicular neoplasm. Urol Case Rep 3(3):89-91

3. Mbaeri TU, Orakwe JC, Nwofor AME, Oranusi CK, Mbonu OO (2013) Ultrasound measurements of testicular volume: comparing the three common formulas with the true testicular volume determined by water displacement. Afr J Urol 19(2):69-73

4. Bergholz R, Koch B, Spieker T, Lohse K (2007) Polyorchidism: a case report and classification. J Pediatr Surg 42(11):1933-1935

5. Hassan A, Elhanbly S, El-Mogy MS, Mostafa T (2013) Triorchidism: two case reports. Andrologia 46(9):1073-1077

6. Aziz W, Rehman KU, Rafique MZ (2016) Doppler ultrasound findings in a patient with primary infertility and triorchidism. BMJ Case Rep 2016:bcr2016215346. https://doi.org/10.1136/bcr-2016-215346

7. Leung AK (1988) Polyorchidism. Am Fam Phys 38(3):153-156

8. Thum G (1991) Polyorchidism: case report and review of literature. J Urol 145(2):370-372

\section{Publisher's Note}

Springer Nature remains neutral with regard to jurisdictional claims in published maps and institutional affiliations.

\section{Submit your manuscript to a SpringerOpen ${ }^{\odot}$ journal and benefit from:}

- Convenient online submission

- Rigorous peer review

- Open access: articles freely available online

- High visibility within the field

- Retaining the copyright to your article

Submit your next manuscript at springeropen.com 